\title{
Control of Mammalian Cochlear Amplification by Chloride Anions
}

\author{
Joseph Santos-Sacchi, ${ }^{1,2,3}$ Lei Song, ${ }^{1}$ Jiefu Zheng, ${ }^{4}$ and Alfred L. Nuttall ${ }^{4,5}$ \\ Sections of ${ }^{1}$ Otolaryngology, ${ }^{2}$ Neurobiology, and ${ }^{3}$ Cellular and Molecular Physiology, Yale University School of Medicine, New Haven, Connecticut 06510, \\ ${ }^{4}$ Oregon Hearing Research Center, Department of Otolaryngology-Head and Neck Surgery, Oregon Health and Science University, Portland, Oregon 97239- \\ 3098, and ${ }^{5}$ Kresge Hearing Research Institute, The University of Michigan, Ann Arbor, Michigan 48109-0506
}

Chloride ions have been hypothesized to interact with the membrane outer hair cell (OHC) motor protein, prestin on its intracellular domain to confer voltage sensitivity (Oliver et al., 2001). Thus, we hypothesized previously that transmembrane chloride movements via the lateral membrane conductance of the cell, $G_{\text {metL }}$, could serve to underlie cochlear amplification in the mammal. Here, we report on experimental manipulations of chloride-dependent $\mathrm{OHC}$ motor activity in vitro and in vivo. In vitro, we focused on the signature electrical characteristic of the motor, the nonlinear capacitance of the cell. Using the well known ototoxicant, salicylate, which competes with the putative anion binding or interaction site of prestin to assess level-dependent interactions of chloride with prestin, we determined that the resting level of chloride in OHCs is near or below $10 \mathrm{~mm}$, whereas perilymphatic levels are known to be $\sim 140$ mm. With this observation, we sought to determine the effects of perilymphatic chloride level manipulations of basilar membrane amplification in the living guinea pig. By either direct basolateral perfusion of the $\mathrm{OHC}$ with altered chloride content perilymphatic solutions or by the use of tributyltin, a chloride ionophore, we found alterations in $\mathrm{OHC}$ electromechanical activity and cochlear amplification, which are fully reversible. Because these anionic manipulations do not impact on the cation selective stereociliary process or the endolymphatic potential, our data lend additional support to the argument that prestin activity dominates the process of mammalian cochlear amplification.

Key words: chloride; hearing; outer hair cell; capacitance; basilar membrane; cochlea

\section{Introduction}

Hallowell Davis coined the term "cochlear amplifier" to signify a boost in hearing capabilities near threshold that is provided by the uniquely mammalian outer hair cell (OHC) (Davis, 1983). The subsequent discovery of electrically evoked OHC mechanical activity provided a very attractive substrate for amplification (Brownell et al., 1985). Nevertheless, processes thought to be characteristic of mammalian cochlear amplification (e.g., spontaneous otoacoustic emissions) have been observed in lower vertebrates lacking OHCs (Manley et al., 2001); such observations have fueled the debate over whether the source of amplification in the mammal is the prestin-containing lateral membrane of the $\mathrm{OHC}$ or the stereociliary transduction apparatus, each of which can potentially provide feedback into the basilar membrane through accessory structures (Santos-Sacchi, 2003). This debate may frame an evolutionary battle between an anionic based mechanism and a cationic based mechanism, the calcium ion underpinning stereocilia-based feedback (Fettiplace et al., 2001; Chan and Hudspeth, 2005) and the chloride ion underpinning

\footnotetext{
Received Oct. 24, 2005; revised March 1, 2006; accepted March 3, 2006.

This work was supported by National Institutes of Health-National Institute on Deafness and Other Communication Disorders Grants DC 00141 (A.L.N.) and DC 00273 (J.S.-S.). We thank Margaret Mazzucco for assistance.

Correspondence should be addressed to Joseph Santos-Sacchi, Otolaryngology, Neurobiology, and Cellular and Molecular Physiology, Yale University School of Medicine, Brandy Memorial Laboratory 246, 333 Cedar Street, New Haven, CT 06510. E-mail: joseph.santos-sacchi@yale.edu.

D0I:10.1523/JNEUROSCI.4548-05.2006

Copyright $\odot 2006$ Society for Neuroscience $\quad$ 0270-6474/06/263992-07\$15.00/0
}

prestin-based feedback (Oliver et al., 2001; Rybalchenko and Santos-Sacchi, 2003).

The manner whereby stereocilia may provide force feedback during auditory stimulation relies on the intracellular action of calcium ions on either myosin molecules or the transduction channel itself, possibly ankyrin-repeat transient receptor potential cation channel, subfamily A, member 1; both of these actions influence apical bundle mechanics (Yamoah and Gillespie, 1996; Gillespie and Corey, 1997; Fettiplace and Ricci, 2003; Corey et al., 2004). In contrast, the lateral membrane motor, prestin (Zheng et al., 2000), is highly sensitive to intracellular anions (Oliver et al., 2001; Rybalchenko and Santos-Sacchi, 2003; Song et al., 2005), in particular, chloride, which has been shown to pass through a lateral membrane conductance, $G_{\text {metL }}$, in a voltage- and tensiondependent manner (Rybalchenko and Santos-Sacchi, 2003). Both ions respectively alter the steady state energy profile of their corresponding transduction mechanism; calcium shifts the stereociliar channel open probability along the mechanical deflection axis (Kennedy et al., 2003), and chloride shifts the area state probability of prestin along the voltage axis (Rybalchenko and Santos-Sacchi, 2003). These ionic effects contribute to force generation in each system, because, as the data imply, conformational changes in the molecules accompany ion binding.

There have been several reports that have focused on the assignment of amplificatory substrate in the mammal. Notably, a prestin knock-out has provided direct evidence that this unusual motor protein (Zheng et al., 2000) is required for OHC electro- 
mechanical activity and cochlear amplification (Liberman et al., 2002). In contrast, studies on isolated mammalian cochleas, which may retain some residual characteristics of cochlear amplification, point to potential contributions from stereociliary mechanics (Fettiplace et al., 2001; Kennedy et al., 2003; Chan and Hudspeth, 2005).

We report here that modulating chloride activity in vitro and in vivo, with cochlear amplifier intact, either directly by basolateral perfusion of the $\mathrm{OHC}$ with altered chloride content solutions or by the use of tributyltin (TBT), a chloride ionophore (Tosteson and Wieth, 1979; Wieth and Tosteson, 1979; Song et al., 2005), alters OHC electromechanical activity and cochlear amplification in a reversible manner. Because these anionic manipulations do not impact on the cation-selective stereociliary process or the endolymphatic potential, our data lend additional support to the argument that prestin activity dominates the process of mammalian cochlear amplification.

\section{Materials and Methods}

\section{In vitro}

The methods for single hair cell recordings were the same as those described in detail previously (Song et al., 2005). Hartley albino guinea pigs were killed with halothane. Temporal bones were excised, and the top three turns of the cochleae were dissected with enzyme treatment $(0.5$ $\mathrm{mg} / \mathrm{ml}$ Dispase I; $10-12 \mathrm{~min}$ ). Individual outer hair cells were isolated by gentle trituration. Isolated single outer hair cells were then studied under whole-cell voltage clamp and were held at $0 \mathrm{mV}$ to eliminate the electrical drive for $\mathrm{Cl}$ across the lateral membrane; therefore, $\mathrm{Cl}$ concentration changes were studied in isolation. A custom made Y-tube perfusion system was used to deliver experimental solutions to isolated OHCs. Perforated patch solutions contained $25 \mathrm{mg} / \mathrm{ml}$ gramicidin in $0.25 \%$ DMSO (Akaike, 1996).

Nonlinear capacitance (NLC) was measured using a continuous highresolution (2.56 ms sampling) two-sine stimulus protocol ( $10 \mathrm{mV}$ peak at both 390.6 and $781.2 \mathrm{~Hz}$ ) superimposed onto a voltage ramp from -150 to $+140 \mathrm{mV}$ (Santos-Sacchi et al., 1998b; Santos-Sacchi, 2004). Capacitance data were fit to the first derivative of a two-state Boltzmann function (Santos-Sacchi, 1991) as follows:

$$
C_{\mathrm{m}}=Q_{\max } \frac{z e}{k T} \frac{b}{(1+b)^{2}}+C_{\operatorname{lin}},
$$

where

$$
b=\exp \left(\frac{-z e\left(V_{\mathrm{m}}-V_{\mathrm{pkCm}}\right)}{k T}\right)
$$

where $Q_{\max }$ is the maximum nonlinear charge moved, $V_{\mathrm{pkcm}}$ (also commonly called $V_{\mathrm{h}}$ ) is voltage at peak capacitance or equivalently at halfmaximum charge transfer, $V_{\mathrm{m}}$ is membrane potential, $z$ is valence, $C_{\operatorname{lin}}$ is linear membrane capacitance, $e$ is electron charge, $k$ is Boltzmann's constant, and $T$ is absolute temperature. NLC was calculated by subtracting linear capacitance $\left(C_{\text {lin }}\right)$ from peak amplitude $\left(C_{\mathrm{pk}}\right)$.

The base extracellular solution contained the following (in $\mathrm{mm}$ ): 140 $\mathrm{NaCl}, 2 \mathrm{CaSO}_{4}, 1.2 \mathrm{MgSO}_{4}$, and 10 HEPES. $\mathrm{Cl}$ concentration was adjusted from 1 to $140 \mathrm{~mm}$ by substituting $\mathrm{Cl}$ with gluconate. Final solutions were adjusted to $\sim 300 \mathrm{mOsm}$ with $\mathrm{D}$-glucose and adjusted to $\mathrm{pH}$ $\sim 7.2-7.3$ with $\mathrm{NaOH}$. Pipette solutions (same as extracellular solution except with the addition of $10 \mathrm{~mm}$ EGTA) contained $\mathrm{Cl}$ ranging from 1 to $140 \mathrm{~mm}$. This composition permitted us to reduce ionic currents (mainly $\mathrm{K}$ currents), which we and others routinely block to measure precisely NLC or gating charge movements (Santos-Sacchi, 1991; Song et al., 2005). The extracellular perfusion solution $(1-140 \mathrm{~mm} \mathrm{Cl})$ also contained graded concentrations of salicylate ( $1 \mu \mathrm{M}$ to $10 \mathrm{~mm})$, with or without the addition of $1 \mu \mathrm{M}$ TBT. For the gramicidin patch experiments, although we attempted to record cells as soon after the animals were killed as possible, we were limited by time required for dissection and cell isolation and by the time after seal formation to achieve good whole cell conditions, namely achieving a series resistance of $<20 \mathrm{M} \Omega$.

\section{In vivo}

Animals and surgery. Pigmented guinea pigs weighing 250-350 g were used in this experiment. After anesthesia, the left bulla was opened via a lateral and ventral approach, and the middle ear muscle tendons were sectioned. A hole $(\sim 0.3 \times 0.4 \mathrm{~mm})$ in the scala tympani of the cochlea was made for measuring the basilar membrane (BM) velocity.

Basilar membrane velocity measurements. The BM velocity at the site corresponding to the frequency near $17 \mathrm{kHz}$ [the characteristic frequency (CF)] was measured from a gold-coated reflective glass bead (10-30 $\mu \mathrm{m}$ in diameter) on the BM using a laser interferometer (Polytec OFV 1102 Laser Vibrometer; Polytec, Waldbronn, Germany). The BM velocity response was evoked by pure tones $(2-24 \mathrm{kHz})$ delivered through a speaker coupled to the ear canal. The output of the interferometer consists of a voltage proportional to the velocity of the targeted bead. The voltage was measured with a lock-in amplifier and recorded by reading the magnitude and phase by computer query via the serial line output from the lock-in amplifier. The vibration of stapes was measured at the end of each experiment and used to compute the gain of BM motion.

Perilymphatic perfusion. For the perilymphatic perfusion, an inlet hole (diameter, $\sim 90 \mu \mathrm{m}$ ) was made in the scala tympani of the basal turn of the cochlea close to the round window niche, and the hole for BM measurement served as fluid outlet. A polyethylene tube with a fine tip (diameter, $\sim 80 \mu \mathrm{m}$ ) was inserted into the inlet hole, and the other end of this tube was connected to a three-way perfusion system that allowed solution replacement. Perfusion was accomplished using a precision syringe pump. Tributyltin $(50 \mu \mathrm{M})$, salicylate $(1-10 \mathrm{mM})$, or combinations of the two agents in artificial perilymph (PL) were infused into the scala tympani at the rate of $2 \mu \mathrm{l} / \mathrm{min}$ with the duration of $10-20 \mathrm{~min}$. Similar results were found with $10 \mu \mathrm{M}$ TBT, but higher concentrations ensured better access across the BM into the spaces of Nuel. The normal artificial perilymph composition is as follows (in $\mathrm{mm}$ ): $132 \mathrm{NaCl}, 3.5 \mathrm{KCl}, 25$ $\mathrm{NaHCO}_{3}, 1.3 \mathrm{CaCl}_{2}, 1.14 \mathrm{MgCl}_{2} 6 \mathrm{H}_{2} \mathrm{O}, 0.51 \mathrm{NaH}_{2} \mathrm{PO}_{4} \mathrm{H}_{2} \mathrm{O}, 5.0$ Tris, 3.3 glucose, and 2.1 urea. For chloride reductions, gluconate substitutions were made. During our treatments, we measured low-frequency cochlear microphonics (CM), a procedure commonly accepted to gauge the $\mathrm{OHC}$ stereociliar transducer function (Patuzzi and Moleirinho, 1998) and endolymphatic potential (EP) to evaluate potential effects on supporting cell $\mathrm{K}$ recycling, which might be expected to compromise the EP (Wangemann et al., 2004).

\section{Results}

\section{Determination of the resting chloride gradient across the OHC membrane}

Our first goal was to characterize resting intracellular levels of chloride in OHCs, using the effects of salicylate on NLC as a quantitative measurement tool. The elucidation of the chloride gradient across the $\mathrm{OHC}$ basolateral membrane is important in understanding our subsequent in vivo manipulations of perilymphatic chloride levels. Peak OHC NLC is reduced in the presence of salicylate (Fig. 1a). The flattening of NLC (and increase at voltages away from the voltage at peak capacitance $\left.\left[V_{\mathrm{pkcm}}\right]\right)$ at high salicylate doses occurs because the voltage sensitivity is depressed across a wider voltage range, an observation completely in line with previous work (Tunstall et al., 1995; Kakehata and Santos-Sacchi, 1996; Santos-Sacchi and Navarrete, 2002). Because salicylate competes for the binding site of chloride on prestin (Oliver et al., 2001), increasing the intracellular concentration of chloride should counter the effects of salicylate. Indeed, the addition of TBT to the extracellular solution induces an influx of chloride down its chemical gradient and a restoration of NLC. We have shown previously that TBT only enhances the flux of chloride when there is a chemical gradient of the anion across the $\mathrm{OHC}$ plasma membrane. Consequently, we found that the effects of salicylate cannot be countered by TBT when intracellular and 

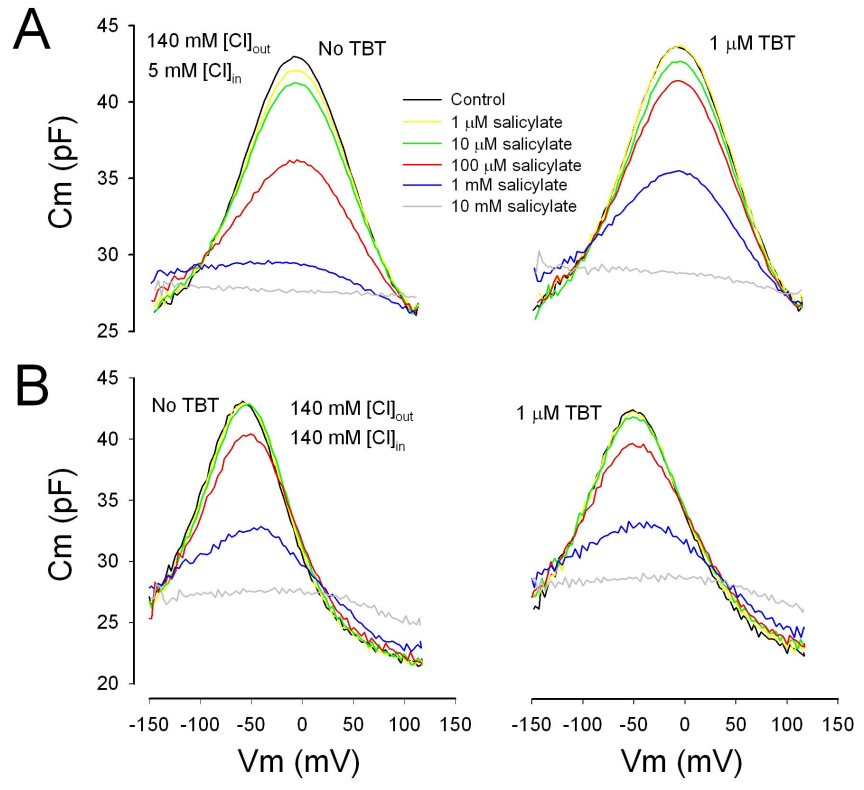

Figure 1. TBT rescues the reduction of salicylate block in NLC under whole-cell voltage clamp. Only in the presence of a chloride gradient can TBT counter this reduction. $\boldsymbol{A}, \boldsymbol{B}$, Effects of graded concentrations of salicylate in the presence of a chloride chemical gradient $(\boldsymbol{A})$ and in the absence of a gradient $(\boldsymbol{B})$. Note also the shifts in operating voltages $\left(V_{\text {pkcm }}\right)$ that accompany changes in intracellular chloride, an increase shifting NLC to hyperpolarizing voltages. Such shifts directly alter the gain of $\mathrm{OHC}$ electromotility at the normal resting potential of the cell (Kakehata and Santos-Sacchi, 1996).

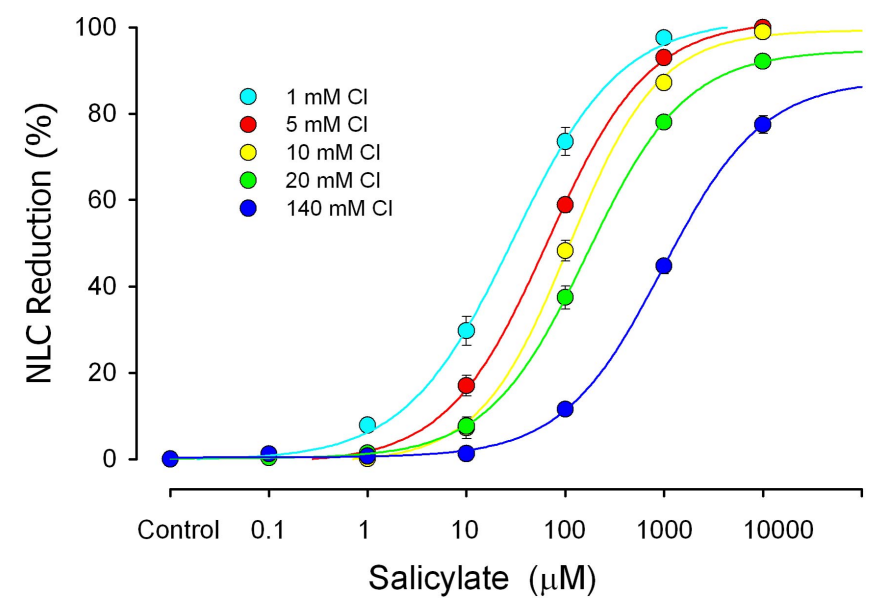

Figure 2. Average dose-response curves (mean $\pm \mathrm{SE} ; n=4-5$ ) for extracellularly applied salicylate block of NLC. Each curve was collected at a different intracellular concentration of chloride. Chloride was unequivocally controlled by matching intracellular and extracellular levels, as we have done previously (Song et al., 2005). Note the leftward shift as intracellular chloride is reduced, indicating a more effective action of salicylate on the motor. Logistic fits provided the following slope and $\mathrm{IC}_{505 \mathrm{sal}}$ values $(1,5,10,20$, and $140 \mathrm{~mm}$ chloride, respectively): $0.79,29.5 \mu \mathrm{m} ; 0.83,77.9 \mu \mathrm{m} ; 0.81,124.0 \mu \mathrm{m} ; 0.86,165 \mu \mathrm{m} ; 0.86,964 \mu \mathrm{m}$. There is no significant difference between slopes at any concentration.

extracellular chloride levels are equal (Fig. 1b). From these data, it is clear that the degree of NLC reduction by salicylate is greatly dependent on intracellular $\mathrm{Cl}$ level. When we reduce the concentration of $\mathrm{Cl}$ on the cytoplasmic aspect of the integral membrane motor protein, the ability of salicylate to reduce remaining NLC increases (Fig. 1a,b, compare left panels). To quantify this observation, we constructed average dose-response functions for a range of salicylate and chloride concentrations (Fig. 2). Although salicylate has its effects on the intracellular aspect of the motor
(Kakehata and Santos-Sacchi, 1996; Oliver et al., 2001), for these experiments, we needed to unequivocally control intracellular $\mathrm{Cl}$ by setting both intracellular and extracellular $\mathrm{Cl}$ concentration to the same level under whole-cell voltage clamp; this is an essential approach that we used previously, because the lateral membrane conductance, $G_{\text {metL }}$, efficiently passes $\mathrm{Cl}$ ions (Rybalchenko and Santos-Sacchi, 2003; Song et al., 2005). Voltage-dependent NLC was quantified by subtracting linear capacitance from peak capacitance, which directly correlates with estimates of maximum motor charge movement $\left(Q_{\max }=4 \mathrm{kT} / \mathrm{ze} \times \mathrm{NLC}\right)$ (SantosSacchi et al., 1998a), determined from fits to the first derivative of a two-state Boltzmann function (see Materials and Methods). $\mathrm{IC}_{50 \mathrm{Sal}}$ for extracellular salicylate action on the motor ranges from $29 \mu \mathrm{M}$ for the $1 \mathrm{~mm}$ intracellular $\mathrm{Cl}$ condition to $964 \mu \mathrm{M}$ for the $140 \mathrm{~mm} \mathrm{Cl}$ condition. From these data, and assuming a salicylate dissociation constant, $K_{\mathrm{d} \text { Sal }}$, of $23.8 \mathrm{~mm}$ (Oliver et al., 2001), we can extract an average chloride dissociation constant, $K_{\mathrm{d} \mathrm{Cl}}=$ $[\mathrm{Cl}] /\left(\mathrm{IC}_{50 \mathrm{Sal}} / K_{\mathrm{d} \mathrm{Sal}}-1\right)$, of $3.4 \pm 0.6 \mathrm{mM}$ (mean $\pm \mathrm{SD}$, from the five tested chloride concentrations), which compares favorably to previous direct estimates of the $K_{\mathrm{d} \mathrm{Cl}}$ of $\sim 6 \mathrm{mM}$ of the motor (Oliver et al., 2001; Song et al., 2005). Although this small difference is likely insignificant, the agreement is actually much better considering that our $\mathrm{IC}_{50 \mathrm{Sal}}$ values are based on extracellular concentrations of salicylate, and we previously demonstrated that intracellular levels will be slightly lower than extracellular levels (Kakehata and Santos-Sacchi, 1996). With our data serving as a calibration standard, we were able to glean an estimate of the intracellular chloride activity of OHCs, a quantity of which the determination is essential in assessing the significance of the role of this anion in cochlear amplification in vivo. Thus, by using the gramicidin patch variant of the whole-cell voltage clamp, we measured the effect of salicylate without perturbing intracellular chloride levels (because gramicidin is impermeant to $\mathrm{Cl}$ ) in the presence of normal, in vivo-like extracellular chloride concentrations, namely $140 \mathrm{~mm}$. Under these conditions, the effectiveness of salicylate on OHCs, which were patched quickly after isolation from the cochlea to abate chloride loading, was similar to that under the $10 \mathrm{~mm}$ intracellular $\mathrm{Cl}$ condition (Fig. $3 \mathrm{~A}$ ), indicating that intracellular chloride rests near $10 \mathrm{~mm}$. OHCs maintained in culture for longer times showed higher chloride levels, and this accumulation of intracellular chloride was accompanied by cell swelling (Fig. $3 B$ ). The similarity between our estimate of $\mathrm{OHC}$ intracellular chloride $(\sim 10 \mathrm{~mm})$ and the $K_{\mathrm{d} \mathrm{Cl}}$ of $\mathrm{OHC}(\sim 6 \mathrm{mM})$ (Oliver et al., 2001; Song et al., 2005) and the opposing interactions between salicylate and intracellular chloride levels set predictable outcomes from comparable manipulations in vivo, if cochlear amplification arises predominantly from $\mathrm{OHC}$ lateral membrane motor activity.

\section{In vivo effects of chloride manipulations}

To test for anionic modulation of cochlear amplification, we directly measured BM motion using a laser interferometer in living guinea pigs, the cochleas of which were surgically exposed. Perfusion of artificial PL (see Materials and Methods for compositions) in the scala tympani was accomplished via a local two-port system in the basal turn and permitted basolateral perfusions of $\mathrm{OHCs}$ without altering the ionic milieu of endolymph that bathed the apically located stereocilia (Fig. 4A). BM motion is sharply tuned to a characteristic frequency determined by place along the cochlea spiral, in our preparation corresponding to $\sim 16-17 \mathrm{kHz}$. The tip of the tuning curve is highly vulnerable, and generally any manipulation of the cochlear fluids or homeostatic environment results in a decrease in cochlear amplification. 

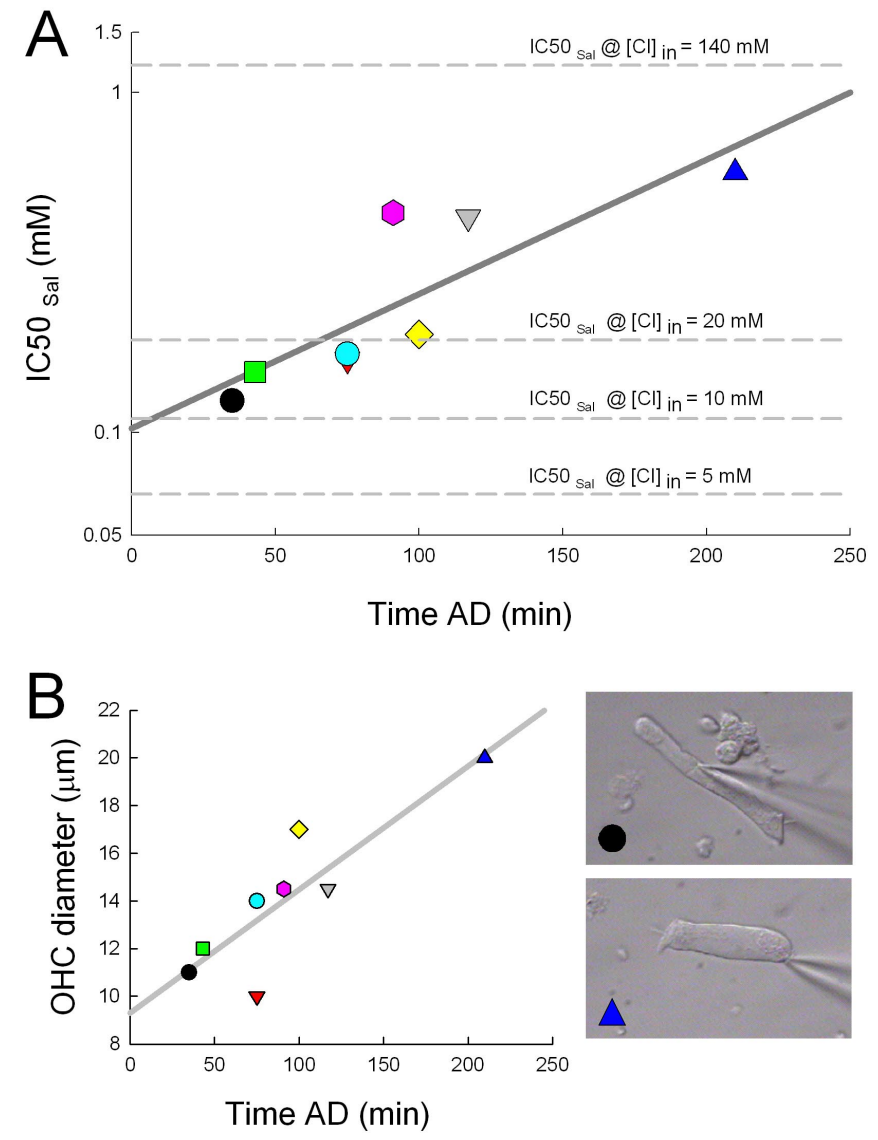

Figure 3. Estimates of $\mathrm{OHC}$ intracellular chloride levels using the gramicidin patch method. $A, \mathrm{IC}_{50 \text { sal }}$ was determined in the presence of $140 \mathrm{~mm}$ extracellular chloride to mimic the in vivo condition. It should be stressed that $\mathrm{IC}_{505 \text { al }}$ measures only evaluate the interactions between intracellular salicylate and chloride on the motor and are not directly influenced by extracellular chloride levels; thus, the $\mathrm{I}_{50 \text { sal }}$ values determined above in Figure $2 \mathrm{~A}$ serve as valid calibrations to estimate intracellular chloride levels regardless of extracellular chloride levels. The plot shows that as the length of time after an animal's death (AD) increased, intracellular chloride increased. For the cases in which quick measurements were made, $\mathrm{I}_{50 \text { sal }}$ was close to that of the value obtained with $10 \mathrm{~mm}$ intracellular chloride, indicating that $\mathrm{OHC}$ chloride levels are near or possibly $<10 \mathrm{~mm}$ for cells under in vivo-like conditions. $\boldsymbol{B}, \mathrm{OHC}$ diameter is a sensitive indicator of cell swelling and shows an increase as time $A D$ increased, corresponding with the simultaneous estimates of intracellular chloride above. $\mathrm{OHC}$ images show one cell recorded at $30 \mathrm{~min}$ and another at $210 \mathrm{~min}$, the latter showing pronounced swelling. The chloride loading after death probably indicates that our measures provide overestimates of intracellular chloride levels. Each symbol in the plots denotes an analysis from an individual cell from different animals $(n=8)$.

Interestingly, to date, no manipulation has been found [other than positive DC electric current (Parthasarathi et al., 2003)] to improve cochlear amplification once compromised. Figure $4 B$ shows $B M$ responses in a sensitive cochlea, where surgical preparation caused minimal loss in sensitivity $(<10 \mathrm{~dB})$, as gauged by preoperation and postoperation auditory compound action potential (CAP) measures. After switching perfusion from normal PL to a PL containing TBT $(50 \mu \mathrm{M})$, a reduction in BM motion was observed (Fig. 4B). An even larger reduction was brought on by a switch to salicylate containing PL ( $5 \mathrm{mM}$ ) and was reversed by washout. Interestingly, in a cochlea where the preparatory manipulations produced a large decrease in CAP sensitivity $(>20$ $\mathrm{dB})$, the action of TBT was to augment acoustically evoked BM vibration (Fig. 4C). Peak amplitude (at best frequency) of the BM mechanical tuning (evoked by $40 \mathrm{~dB}$ sound pressure level acousti) with artificial perilymph and TBT perfusion into the scala tympani showed an enhancement of $4.42 \pm 1.16 \mathrm{~dB}$ (mean $\pm \mathrm{SD} ; n=5$; paired $t$ test, $p<0.001$ ). In linear terms, this is a $>50 \%$ increase in response ( $1.66 \pm 0.22)$. This highly unusual and repeatable finding may indicate that intracellular chloride is normally poised at a level that is optimal, and that changes in intracellular chloride activity can have either positive or negative effects on BM tuning, depending on initial condition of the preparation (i.e., perhaps preparative procedures altered $\mathrm{Cl}$ levels and our perfusions re-established preinsult conditions). Again, in this animal, salicylate caused a decrease in BM motion, but the combination of salicylate and TBT resulted in an effect less detrimental than salicylate alone, reminiscent of the rescuing effect of TBT on the block by salicylate of NLC in vitro. Finally, we directly tested the effects of low-chloride PL (5 mM; substitution with gluconate) on BM motion. A profound loss of cochlear amplification was found (loss of sharp tip region and shift of CF to lower frequencies), which was fully reversible after reperfusion with normal PL (Fig. 4D). The addition of TBT to the normal perfusion again augmented $\mathrm{BM}$ motion above initial conditions. However, TBT was unable to counter the loss induced by low-chloride perfusions, because very little gradient in chloride existed across the OHC plasma membrane. $\mathrm{CM}$ at sub-CF frequencies $(0.5$ $\mathrm{kHz}$ ), which report on stereociliary forward transduction in OHCs (Patuzzi and Moleirinho, 1998), were unchanged or slightly increased by low chloride or salicylate perfusions, as expected from previous work (Desmedt and Robertson, 1975; Fitzgerald et al., 1993). This implies that our treatments do not affect stereociliary processes, including the transducer Ca sensitivity. Additionally, we measured the EP in three animals under low-chloride conditions and found it to be unaffected $(<3 \mathrm{mV}$ variations). Together, the in vitro and in vivo data indicate the powerful role played by chloride in cochlea amplification and highlight the importance of the prestin-containing lateral membrane and its conductance, $G_{\text {metL }}$.

\section{Discussion}

The problem of assignment of cochlear amplification to the apical or lateral membrane of the $\mathrm{OHC}$ may reduce to a test of the effects of modulating chloride levels around the basolateral region of the OHCs, a manipulation that should not interfere with the cationic workings of the proposed stereociliar mechanism. Indeed, this general approach has been used to assess the contribution of calcium ion effects on the role of stereocilia in amplification, in which modulation of endolymphatic ionic makeup was performed while maintaining perilymphatic makeup (Chan and Hudspeth, 2005). We approached this issue by directly measuring cochlear amplification on the BM in vivo, along with complimentary measures of isolated OHC activity under whole-cell voltage clamp. Thus, in vitro, we measured the electromechanical activity of isolated OHCs by gauging the motor-generated NLC of the cell under whole-cell voltage clamp (Santos-Sacchi, 1991), and in vivo we measured BM vibratory velocity directly (Nuttall et al., 1991). Interactions among three manipulations of the lateral membrane motor were made using the following: (1) salicylate, a well known ototoxicant that works directly on the motor (Tunstall et al., 1995; Kakehata and Santos-Sacchi, 1996) via its interaction with the chloride binding site of the motor (Oliver et al., 2001); (2) TBT, an ionophore that promotes $\mathrm{OHC} \mathrm{Cl} \mathrm{flux} \mathrm{down}$ its chemical gradient (Song et al., 2005); and (3) extracellular chloride levels, which will influence intracellular chloride activity via $G_{\text {metL }}$ (Rybalchenko and Santos-Sacchi, 2003; Song et al., 2005). We found that in intact OHCs, intracellular chloride rests at level well below that of extracellular chloride, being $\sim 10 \mathrm{~mm}$ or 
less intracellularly. Manipulations of extracellular chloride, the effects of which arose from the chemical gradient of chloride across the OHC membrane, had pronounced effects on motor charge movement in vitro and markedly and reversibly affected cochlear amplification on the basilar membrane.

Our data provide clear evidence that the gain of cochlear amplification is tied directly to the gain of $\mathrm{OHC}$ motor activity, the electrical correlates of which are the amount of motor charge moved and the voltage range over which the motors operate, both of which are influenced by intracellular chloride and salicylate (Tunstall et al., 1995; Kakehata and Santos-Sacchi, 1996; Oliver et al., 2001; Rybalchenko and Santos-Sacchi, 2003; Song et al., 2005). Effects on stereociliar transduction and EP were absent, lending support to a direct effect on the OHC lateral membrane motor protein, prestin. Interestingly, although salicylate was found to affect emissions in the Tokay gecko (Stewart and Hudspeth, 2000), the hair cells of which lack prestin, there is no direct action of salicylate on the stereociliar mechanoelectrical transducer (MET) channels (Kimitsuki et al., 1994). Although a variety of physiological factors affect the gain of OHC motor activity, including membrane tension (Iwasa, 1993; Gale and Ashmore, 1994; Kakehata and Santos-Sacchi, 1995), temperature (Santos-Sacchi and Huang, 1998), and phosphorylation (Huang and Santos-Sacchi, 1993; Szonyi et al., 1999; Frolenkov et al., 2000; Deak et al., 2005), the recruitment of a ubiquitous anion to drive our exquisite sense of hearing bares an underlying simplicity in design for such a complicated endorgan.

\section{How might chloride work on cochlear amplification?}

Clearly, it has been shown that chloride ions have a powerful effect on prestin activity via an intracellular binding or interaction site (Oliver et al., 2001; Rybalchenko and Santos-Sacchi, 2003; Song et al., 2005). The effect may not simply apply to chloride interactions but also to interactions with other anions, for example, sulfate. Interestingly, whereas sulfate was initially found by Oliver et al. (2001) to be ineffective in influencing prestin activity, namely an inability to support NLC, we and others have since found that sulfate can support NLC in intact OHCs while shifting $V_{\mathrm{h}}$ to very depolarized potentials (Rybalchenko and Santos-Sacchi, 2003; Ashmore, 2005; Fettiplace, 2005). Nevertheless, the physiological abundance of chloride indicates that it may be the major player in $\mathrm{OHC}$ function.

It is conceivable, however, that manipulating perilymphatic chloride could have effects within the cochlear aside from the $\mathrm{OHC}$ lateral membrane. For example, chloride transport is thought to play a role in $K$ recycling within the inner ear (Wangemann et al., 2004). Our observation that the endolymphatic potential is unperturbed during our manipulations rules out such a possibility, because $K$ recycling interference would compromise
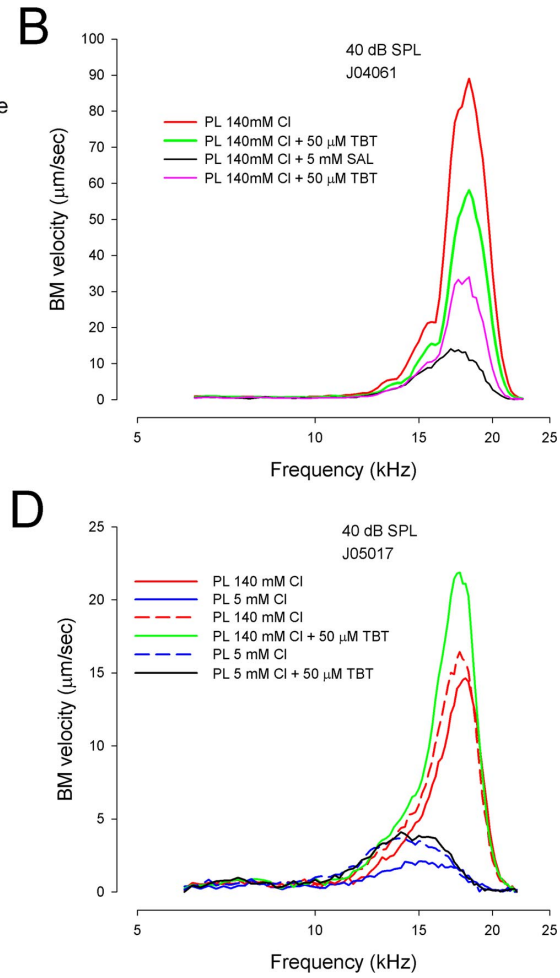

Frequency $(\mathrm{kHz})$

Figure 4. $\quad \boldsymbol{A}$, Schematic of in vivo preparation. See Materials and Methods for details. $\boldsymbol{B}, \mathrm{BM}$ responses to acoustic stimulation 列 perfusion may stem from previous TBT treatment or the time between data collections. For visual clarity, sound pressure is plotted on a linear scale; frequency is plotted logarithmically.

the EP. Additionally, it is well known that OHC turgor can be modulated by extracellular chloride manipulations (Cecola and Bobbin, 1992; Song et al., 2005), and that electromotility can be modulated by changes in membrane tension (Iwasa, 1993; Gale and Ashmore, 1994; Kakehata and Santos-Sacchi, 1995). Indeed, we hypothesized that cochlear amplification could be controlled by turgor pressure changes in OHCs (Kakehata and SantosSacchi, 1995). Thus, it may be that turgor pressure changes accompanied by chloride flux contributes to our in vivo measures (in vitro we control turgor pressure and show chloride effects directly). We note, however, that in the absence of a chloride conductance and gradient, such effects on turgor pressure would not arise, because it is the flux of chloride that instigates water movement into and out of the OHC. Interestingly, manipulations of perilymphatic osmolarity in vivo have been found to modulate otoacoustic emissions, and the auditory compound action potential (Choi and Spector, 2005). Thus, it may be that two mechanisms known to modulate the OHC lateral membrane may contribute to the chloride effects we observed, although the effects we observe are larger than those observed with osmolarity manipulations.

\section{The lateral membrane as forward and reverse transducer}

The apparent voltage-dependent nature of $\mathrm{OHC}$ electromotility necessarily encumbers the effectiveness of the presumed stimulus 
(receptor potentials) in driving high-frequency mechanical activity. This conundrum derives from the low-pass resistor-capacitor (RC) filter effect of the plasma membrane of the cell (SantosSacchi, 1989, 1992; Housley and Ashmore, 1992), estimated to be between 50 and $800 \mathrm{~Hz}$. Consequently, receptor potentials generated by stereociliary transduction elements will be reduced at high acoustic frequency, resulting in diminished feedback into the basilar membrane. Although several proposals have been advanced to understand how the OHC may deal with this difficulty (Santos-Sacchi et al., 1998a; Kakehata and Santos-Sacchi, 1995; Dallos and Evans, 1995; Spector et al., 2003), the issue remains unresolved.

We presented previously a hypothesis that the $\mathrm{OHC}$ lateral membrane, with its mechanically active conductance, $G_{\text {metL }}$, may have usurped the role of stereocilia by fluxing anions, rather than cations, during acoustic stimulation (Rybalchenko and SantosSacchi, 2003; Santos-Sacchi, 2003). Notably, acoustically driven motions of the organ of Corti have been shown to deform the OHC soma (Fridberger and De Monvel, 2003), potentially gating $G_{\text {metL }}$ at acoustic rates. Furthermore, tuned mechanical responses of the isolated $\mathrm{OHC}$ induced by water-jet driven mechanical stimulation of the lateral membrane can be blocked by polylysine (Brundin et al., 1989; Brundin and Russell, 1994), a chemical that partially blocks $G_{\text {metL }}$ (Rybalchenko and Santos-Sacchi, 2003). Such a cellular adaptation of forward transduction may offer a means to overcome the RC filter problem. Basically, the anion driven conformational state dependence of prestin would be unencumbered by the low-pass filtering effects of the $\mathrm{OHC}$ membrane but would only depend on the kinetics of anion current flow and submembranous accumulation and clearing. We have shown mechanical gating of $G_{\text {metL }}$ in the kilohertz range (Rybalchenko and Santos-Sacchi, 2003), but additional work on this hypothesis is required.

Although our data provide support for an evolutionary switch from cation to anion control, it was shown recently that manipulations of Ca-dependent stereociliar mechanics altered a remaining nonlinearity present in an in vitro explant of the mammalian cochlea, suggesting that bundle mechanics could partly contribute to mammalian cochlear amplification (Chan and Hudspeth, 2005). Thus, it appears that the evolution of the OHC and its mechanically active lateral membrane may have occurred to supplement an already primitive amplificatory system, which, for the mammal, begged an extra boost.

\section{References}

Akaike N (1996) Gramicidin perforated patch recording and intracellular chloride activity in excitable cells. Prog Biophys Mol Biol 65:251-264.

Ashmore J (2005) Prestin is an electrogenic anion transporter. Paper presented at 42nd Workshop on Inner Ear Biology, Tubingen, Germany, September.

Brownell WE, Bader CR, Bertrand D, de Ribaupierre Y (1985) Evoked mechanical responses of isolated cochlear outer hair cells. Science 227:194-196.

Brundin L, Russell I (1994) Tuned phasic and tonic motile responses of isolated outer hair cells to direct mechanical stimulation of the cell body. Hear Res 73:35-45.

Brundin L, Flock A, Canlon B (1989) Sound-induced motility of isolated cochlear outer hair cells is frequency-specific. Nature 342:814-816.

Cecola RP, Bobbin RP (1992) Lowering extracellular chloride concentration alters outer hair cell shape. Hear Res 61:65-72.

Chan DK, Hudspeth AJ (2005) $\mathrm{Ca}^{2+}$ current-driven nonlinear amplification by the mammalian cochlea in vitro. Nat Neurosci 8:149-155.

Choi C, Spector A, Oghalai J (2005) Perilymph osmolarity modulates cochlear function. Midwinter Meeting of the Association for Research in Otolaryngology, February.

Corey DP, Garcia-Anoveros J, Holt JR, Kwan KY, Lin SY, Vollrath MA,
Amalfitano A, Cheung EL, Derfler BH, Duggan A, Geleoc GS, Gray PA, Hoffman MP, Rehm HL, Tamasauskas D, Zhang DS (2004) TRPA1 is a candidate for the mechanosensitive transduction channel of vertebrate hair cells. Nature 432:723-730.

Dallos P, Evans BN (1995) High-frequency motility of outer hair cells and the cochlear amplifier. Science 267:2006-2009.

Davis H (1983) An active process in cochlear mechanics. Hear Res 9:79-90.

Deak L, Zheng J, Orem A, Du GG, Aguinaga S, Matsuda K, Dallos P (2005) Effects of cyclic nucleoticles on the function of prestin. J Physiol (Lond) 563:483-496.

Desmedt JE, Robertson D (1975) Ionic mechanism of the efferent olivocochlear inhibition studied by cochlear perfusion in the cat. J Physiol (Lond) 247:407-428

Fettiplace R, Ricci AJ (2003) Adaptation in auditory hair cells. Curr Opin Neurobiol 13:446-451.

Fettiplace R, Ricci AJ, Hackney CM (2001) Clues to the cochlear amplifier from the turtle ear. Trends Neurosci 24:169-175.

Fitzgerald JJ, Robertson D, Johnstone BM (1993) Effects of intra-cochlear perfusion of salicylates on cochlear microphonic and other auditory responses in the guinea pig. Hear Res 67:147-156.

Fridberger A, De Monvel JB (2003) Sound-induced differential motion within the hearing organ. Nat Neurosci 6:446-448.

Frolenkov GI, Mammano F, Belyantseva IA, Coling D, Kachar B (2000) Two distinct $\mathrm{Ca}^{2+}$-dependent signaling pathways regulate the motor output of cochlear outer hair cells. J Neurosci 20:5940-5948.

Gale JE, Ashmore JF (1994) Charge displacement induced by rapid stretch in the basolateral membrane of the guinea-pig outer hair cell. Proc R Soc Lond B Biol Sci 255:243-249.

Gillespie PG, Corey DP (1997) Myosin and adaptation by hair cells. Neuron 19:955-958.

Housley GD, Ashmore JF (1992) Ionic currents of outer hair cells isolated from the guinea-pig cochlea. J Physiol (Lond) 448:73-98.

Huang G-J, Santos-Sacchi J (1993) Metabolic control of OHC function: phosphorylation and dephosphorylation agents shift the voltage dependence of motility related capacitance. Meeting of the Association for Research in Otolaryngology, St Petersburg, FL, February.

Iwasa KH (1993) Effect of stress on the membrane capacitance of the auditory outer hair cell. Biophys J 65:492-498.

Kakehata S, Santos-Sacchi J (1995) Membrane tension directly shifts voltage dependence of outer hair cell motility and associated gating charge. Biophys J 68:2190-2197.

Kakehata S, Santos-Sacchi J (1996) Effects of salicylate and lanthanides on outer hair cell motility and associated gating charge. J Neurosci 16:4881-4889.

Kennedy HJ, Evans MG, Crawford AC, Fettiplace R (2003) Fast adaptation of mechanoelectrical transducer channels in mammalian cochlear hair cells. Nat Neurosci 6:832-836.

Kimitsuki T, Nakagawa T, Hisashi K, Komune S, Uemura T (1994) The effects of ototoxic drugs on mechano-electric transduction channels in chick cochlear hair cells. Eur Arch Otorhinolaryngol 251 [Suppl 1]:S53-S56.

Liberman MC, Gao J, He DZ, Wu X, Jia S, Zuo J (2002) Prestin is required for electromotility of the outer hair cell and for the cochlear amplifier. Nature 419:300-304.

Manley GA, Kirk DL, Koppl C, Yates GK (2001) In vivo evidence for a cochlear amplifier in the hair-cell bundle of lizards. Proc Natl Acad Sci USA 98:2826-2831.

Nuttall AL, Dolan DF, Avinash G (1991) Laser doppler velocimetry of basilar-membrane vibration. Hearing Res 51:203-213.

Oliver D, He DZ, Klocker N, Ludwig J, Schulte U, Waldegger S, Ruppersberg JP, Dallos P, Fakler B (2001) Intracellular anions as the voltage sensor of prestin, the outer hair cell motor protein. Science 292:2340-2343.

Parthasarathi AA, Grosh K, Zheng J, Nuttall AL (2003) Effect of current stimulus on in vivo cochlear mechanics. J Acoust Soc Am 113:442-452.

Patuzzi R, Moleirinho A (1998) Automatic monitoring of mechanoelectrical transduction in the guinea pig cochlea. Hear Res 125:1-16.

Rybalchenko V, Santos-Sacchi J (2003) $\mathrm{Cl}^{-}$flux through a non-selective, stretch-sensitive conductance influences the outer hair cell motor of the guinea-pig. J Physiol (Lond) 547:873-891.

Santos-Sacchi J (1989) Asymmetry in voltage-dependent movements of isolated outer hair cells from the organ of Corti. J Neurosci 9:2954-2962. 
Santos-Sacchi J (1991) Reversible inhibition of voltage-dependent outer hair cell motility and capacitance. J Neurosci 11:3096-3110.

Santos-Sacchi J (1992) On the frequency limit and phase of outer hair cell motility: effects of the membrane filter. J Neurosci 12:1906-1916.

Santos-Sacchi J (2003) New tunes from Corti's organ: the outer hair cell boogie rules. Curr Opin Neurobiol 13:459-468.

Santos-Sacchi J (2004) Determination of cell capacitance using the exact empirical solution of $\mathrm{dY} / \mathrm{dCm}$ and its phase angle. Biophys J 87:714-727.

Santos-Sacchi J, Huang GJ (1998) Temperature dependence of outer hair cell nonlinear capacitance. Hear Res 116:99-106.

Santos-Sacchi J, Navarrete E (2002) Voltage-dependent changes in specific membrane capacitance caused by prestin, the outer hair cell lateral membrane motor. Pflügers Arch 444:99-106.

Santos-Sacchi J, Kakehata S, Kikuchi T, Katori Y, Takasaka T (1998a) Density of motility-related charge in the outer hair cell of the guinea pig is inversely related to best frequency. Neurosci Lett 256:155-158.

Santos-Sacchi J, Kakehata S, Takahashi S (1998b) Effects of membrane potential on the voltage dependence of motility-related charge in outer hair cells of the guinea-pig. J Physiol (Lond) 510:225-235.

Song L, Seeger A, Santos-Sacchi J (2005) On membrane motor activity and chloride flux in the outer hair cell: lessons learned from the environmental toxin tributyltin. Biophys J 88:2350-2362.

Spector A, Popel AS, Brownell W (2003) Piezoelectric properties enhance outer hair cell high-frequency response. In: Biophysics of the cochlea: from molecules to models (Gummer A, ed), pp 51-54. Singapore: World Scientific Publishing.

Stewart CE, Hudspeth AJ (2000) Effects of salicylates and aminoglycosides on spontaneous otoacoustic emissions in the Tokay gecko. Proc Natl Acad Sci USA 97:454-459.

Szonyi M, He DZ, Ribari O, Sziklai I, Dallos P (1999) Cyclic GMP and outer hair cell electromotility. Hear Res 137:29-42.

Tosteson MT, Wieth JO (1979) Tributyltin-mediated exchange diffusion of halides in lipid bilayers. J Gen Physiol 73:789-800.

Tunstall MJ, Gale JE, Ashmore JF (1995) Action of salicylate on membrane capacitance of outer hair cells from the guinea-pig cochlea. J Physiol (Lond) 485:739-752.

Wangemann P, Itza EM, Albrecht B, Wu T, Jabba SV, Maganti RJ, Lee JH, Everett LA, Wall SM, Royaux IE, Green ED, Marcus DC (2004) Loss of KCNJ10 protein expression abolishes endocochlear potential and causes deafness in Pendred syndrome mouse model. BMC Med 2:30.

Wieth JO, Tosteson MT (1979) Organotin-mediated exchange diffusion of anions in human red cells. J Gen Physiol 73:765-788.

Yamoah EN, Gillespie PG (1996) Phosphate analogs block adaptation in hair cells by inhibiting adaptation-motor force production. Neuron 17:523-533.

Zheng J, Shen W, He D, Long K, Madison L, Dallos P (2000) Prestin is the motor protein of cochlear outer hair cells. Nature 405:149-155. 